\title{
Microbial and Economical Studies of Jamun Beverages Prepared by Alternative Sweeteners
}

\author{
Bhawna Panda ${ }^{1}$, H. G. Sharma ${ }^{1}$, Abhay Bisen ${ }^{2}$ and Krishnakant Rajak ${ }^{2}$ \\ ${ }^{1}$ Department of Fruit Science, college of Agriculture, IGKV, Raipur-492012, India \\ ${ }^{2}$ SKS College of Agriculture and Research Station, Rajnandgaon, IGKV-441491, India \\ *Corresponding author
}

\section{A B S T R A C T}

\section{Keywords}

Jamun, Nectar,

RTS, Alternative

sweeteners,

Microbial,

Economical

Article Info

Accepted:

04 November 2019

Available Online:

10 December 2019
Jamun nectar and RTS prepared from alternative sweeteners were evaluated through microbial counts and economical analysis. The experimental material consisted of 15 treatments of alternative sweeteners and one treatment of $100 \%$ sugar combination each for nectar and RTS. The treatments were replicated three times in Completely Randomized Design (CRD). In the experiment alternative sweeteners like Erythrtol, Stevia and Equal were used for the preparation jamun nectar and RTS beverages. The minimum population density was observed in $100 \%$ Stevia $\left(\mathrm{T}_{\mathbf{5}}\right)$ and the increase in microbial growth was within the permissible level. Application of heat during processing irrespective of holding time reduced the microbial load. The highest net return and benefit: cost ratio was recorded in the treatment of $100 \%$ Erythritol $\left(\mathrm{T}_{1}\right)$ while, both was recorded lowest under the treatment $100 \%$ Sugar $\left(\mathrm{T}_{0}\right)$ respectively.

\section{Introduction}

Syzygium cumini is also known as Syzygium jamunum and Eugenia cumini. Other common names are Jambul, Black Plum, Java Plum, Indian Blackberry, Jamblang, Jamun etc. The tree fruits once in a year and the berries are sweetish sour to taste. The Jamun is prolific and regular bearer tree. Fruits ripen in JuneJuly or on the onset of rains and takes about 34 months to ripen after full bloom. Fruit colour change from green to deep-red or bluish-black at full ripening stage. Berry appears oblong, ovoid and crimson black in colour when fully ripe. Fruits from grafted tree are large and deliciously sweet but slightly sour in taste (Pathak and Pathak, 1993). The Jamun fruit is good source of iron, sugars, minerals, protein and carbohydrate etc. Fully ripened fruits are eaten as fresh fruit and can be processed into products like squash, wine, vinegar jelly, jam and pickles. Jamun has 
special significance for medicinal properties. It also pertains to better antioxidant, antibacterial, anticarsinogenic, cardiovascular properties. Jamunfruits are universally accepted for medicinal purpose especially for curing diabetes because of its good effects on pancreas (Joshi, 2001). The fruit or its juice and the seed contain a biochemical called 'jamboline' which is believed to check the pathological conversion of starch into sugar in case of increased production of glucose in blood of human body. Leaf extract of Jamun reduces the radiation induced DNA damage in the cultured human peripheral blood lymphocytes (Prince et al., 2003).

The increase of fruit nectar has been popularized significantly in recent years. India is the second largest country for fruit production in the world after china but the farmers are facing the big challenge to get appropriate value for their produce. Most of fruit crops are seasonal there for time of harvesting of each commodity is constant so, that commodities come in the market at particular time that causes market glut. To reduce the market glut and perishable in nature of fruits, it must be marketed immediately after harvesting without primary processing (Choudhury, 2006). Now a days nectar and ready-to-serve (RTS) beverages globalized as an instant source of energy drink and its market value is increase day by day these are available in various flavour in 200 $\mathrm{ml}, 500 \mathrm{ml}$, 1lit and 2 lit of packaging, the values of $200 \mathrm{ml}$ pack varies for 10 to 15 rupees which has cost benefit ratio 1:9. Sweetness is a strong stimulant of food/drink intake. Sugar provides sweetness and also contributes towards energy intake. The development of products containing low calorie sweeteners could therefore allow consumers to enjoy sweet foods and drinks with fewer calories. Due to properties of low blood glucose response, low energy value alternative sweeteners have been considered as good sugar substitutes in food applications, especially in beverages which are the primary sources for sugar (Livesey 2006; Maguire 2006). Alternative sweeteners are used in place of normal table sugar and can be made from chemicals or some natural herbs. There are various kinds of sweeteners available in the market which has specific chemical name and different trade name. Most of them do not contain any calories such as Erythritol, equal, stevia etc. are used in very small amounts because of their concentrated sweetening power.

\section{Materials and Methods}

\section{Preparation of nectar and RTS}

For the experimentation, fully-ripened and uniform sized fruits of jamun were procured from the market. Unripe, diseased, damaged and off type fruits were strictly discarded. The selected fruits were thoroughly washed with clean tap water to remove dirt and dusts particles adhered to the pericarp of the fruit and then allowed to dried for removal of excess moisture from the fruit surface, otherwise it permits the entry for harmful micro-organism and prone to spoilage during storage. One kilogram ripened jamun fruits were crushed manually with hands without damaging the seeds. The extracted pulp without seeds was heated to $50^{\circ} \mathrm{C}$ and passed through a fine muslin cloth. After extraction of juice, 20 per cent pulp for nectar and 10 per cent pulp for RTS were taken. The volume of the final product was maintained by adding water to each recipe combination in each replication. A calculated amount of sugar \& alternative sweeteners was added in the juice to adjust the total soluble solids as $18 \%$ in the recipe for nectar and as $15 \%$ for RTS. The acidity was maintained to $0.3 \%$ in the final product by the addition of required amount of citric acid. The prepared nectar and RTS beverages were again filtered by sieving 
through a muslin cloth to obtain a product of uniform consistency. The product was poured into hot, sterilized bottles of $200 \mathrm{ml}$ capacity and corked air-tight. The filled bottles were pasteurized in boiling water till the temperature of product reaches $100^{\circ} \mathrm{C}$. It took about 15 minutes to attain required temperature. The bottles of nectar and RTS beverages were kept at ambient condition for further studies upto 90 days.

\section{Microbial analysis of Jamun nectar and RTS}

Microbial analysis of jamun nectar and RTS was done by serial dilution plating method (Rao, 1988). For microbial counting, serial dilutions of the samples were done by taking 1 $\mathrm{ml}$ of sample in $9 \mathrm{ml}$ sterilized water in a dilution tube and it was shaken. After shaking, the dilution tube (No. 1) was kept for few minutes, in this way 101 dilution of the sample was obtained. After that $1.0 \mathrm{ml}$ of this suspension from dilution tube No. 1 was drawn out with the help of micro pipette and transferred to another dilution tube No. 2 containing $9 \mathrm{ml}$ sterilized water, resulting $10^{2}$ dilutions. Again $1.0 \mathrm{ml}$ suspension was drawn from dilution tube No. 2 for $10^{3}$ dilutions and again $1.0 \mathrm{ml}$ suspension was drawn from dilution tube No. 3 for $10^{4}$ dilutions this way serial dilution of sample was carried out upto desirable dilution and finally a complete set of $10^{5}$ dilution of each sample was obtained. Potato Dextrose Agar medium (PDA) was used for counting microbial colonies (Rao, 1988).

\section{Composition of the media}

Potato slice (Peeled)-200 gm, Dextrose- 20.0 gm, Agar -20.0 gm, Distilled water-1000 ml

Two hundred peeled potato slices were taken and boiled $1 / 2$ litre water till softening. Then extract of potato was taken and slices were discarded. In another $1 / 2$ litre of water, $20 \mathrm{gm}$ dextrose and $20 \mathrm{gm}$ agar-agar was mixed till dissolved. Then after potato extract and glucose-agar solution were mixed thoroughly and final volume 1 litre was make up by adding extra sterilized water and filtered with sieve to remove the impurities from medium. The prepared medium was equally transferred in conical flasks $(200 \mathrm{ml})$. Each flask had 150 $\mathrm{ml}$ medium and plugged with non absorbent cotton. Thereafter, medium was used sterilized in autoclave at $15 \mathrm{lbs} / \mathrm{inch}^{2}$ for 15 minutes. After sterilization it was kept in refrigerator and used for further research work.

About $20 \mathrm{ml}$ sterilized medium was poured in to the sterilized petri plates containing $1 \mathrm{ml}$ aliquot of appropriate dilution at the bottom which was drawn out from the dilution tube with the help of sterilized tips of micro pipette and the plates were incubated at $25^{\circ} \mathrm{C}$ in the incubator. Counting of microbial colonies started after 24 hours of incubation. Counted colonies were marked with the instant marker to avoid the repetition in counting and the process was done on colony counter. Planting each samples was done in triplicate and mean value were worked out for each samples. One control was also incorporated with each set of planting. After counting of colonies, microbial population was calculated on the basis of per $\mathrm{ml}$ of sample using following formula (Schmidt and Caldwell, 1967).

No. of microbes/ $\mathrm{ml}$ of sample

No. of colony forming

units (CFU) X Dilution

Aliquot taken

Benefit: Cost (B: C) ratio of jamun nectar and RTS

Treatment wise cost of production was worked out. The total expenditure on production and management of jamun nectar and RTS was 
recorded in terms of Rs. The gross monetary return for hundred bottles was worked out considering the average prevailing price for jamun nectar and RTS and net return was calculated by subtracting the cost of production from gross returns then the B: C ratio was worked out by using following formula.

\section{$\mathrm{B}: \mathrm{C}$ ratio $=$}

Net return

Cost of production

\section{Results and Discussion}

\section{Microbial analysis of jamun nectar}

Keeping in view of estimated microbial population per $\mathrm{ml}$ of sample by dilution planting method, $100 \%$ Stevia $\left(\mathrm{T}_{5}\right)$ showed the minimum population density followed by $50 \%$ Stevia $+50 \%$ Equal $\left(\mathrm{T}_{15}\right)$ treatment and maximum microbial population density was recorded in $50 \%$ Equal $+50 \%$ Sugar $\left(\mathrm{T}_{11}\right)$ treatment (Table 1).

\section{Microbial analysis of jamun RTS}

Keeping in view of estimated microbial population per $\mathrm{ml}$ of sample by dilution planting method, $100 \%$ Stevia $\left(\mathrm{T}_{5}\right)$ showed the minimum population density followed by $50 \%$ Stevia $+50 \%$ Equal $\left(\mathrm{T}_{15}\right)$ and the maximum population density was recorded in 50\% Equal $+50 \%$ Sugar $\left(\mathrm{T}_{11}\right)$ (Table 2$)$.

However, the rate of increase and decrease in both nectar and RTS, microbial colony load was affected by various treatment i.e., juice extraction methods, recipe and their combinations. Similar finding was reported by Goyle and Ojha (1998) who studied the effect of microbial load and sensory attributes of orange pulp and reported that the total microbial counts increased in the first week and then decreased considerably from the second to the fourth week of storage. The data revealed the microbial growth pattern at various time intervals and systematic increased in dilution of the jamun nectar and RTS beverage sample corresponding to the storage time. The growth was found to be highest at the $30^{\text {th }}$ day of the storage period which may be attributed to the chemical changes, specifically alteration in the $\mathrm{pH}$ of the system that would take place resulting from the presence of the chemical preservatives in the samples. Similar results were also reported Markam and Singh (2012) in custard apple RTS beverage. They reported that microbial population increased from 0 days up to 30 days then decreased with advancement of storage period. Li et al., (1989) who studied the effect of acidification, combination of acidification and low temperature and sorbates on the storage of orange juice and reported that relatively high concentrations of vitamin $\mathrm{C}$ were present in orange containing high population of microorganisms. These observations are in close agreement with the findings of Upaleet al., (2010) in jamun nectar and RTS beverages and Yadavet al., (2012) in Banana RTS beverage. Thakur et al., (2000) also studied on physico-chemical and microbial qualities of Kinnow juice and concluded that low microbial count was detected in the concentrate at the beginning, which increased with the advancement of storage.

\section{Benefit: Cost ratio of nectar}

Data pertaining to effect of different recipe treatments on the Benefit: cost ratio of jamun nectar is presented Table 3 . 
Table.1 Effect of different recipe treatments on microbial population dynamics of stored jamun nectar

\begin{tabular}{|c|c|c|c|c|}
\hline \multirow[t]{2}{*}{ Treatments } & \multicolumn{4}{|c|}{ Storage periods (days) } \\
\hline & $\mathbf{0}$ & 30 & 60 & 90 \\
\hline$T_{0}: 100 \%$ Sugar & 16 & 33 & 29 & 28 \\
\hline $\mathrm{T}_{1}: \mathbf{1 0 0 \%}$ Erythritol & 4 & 13 & 11 & 9 \\
\hline $\mathrm{T}_{2}: \mathbf{7 5 \%}$ Erythritol + $25 \%$ Sugar & 9 & 19 & 18 & 15 \\
\hline $\mathrm{T}_{\mathbf{3}}: \mathbf{5 0 \%}$ Erythritol $+\mathbf{5 0 \%}$ Sugar & 11 & 29 & 26 & 23 \\
\hline $\mathrm{T}_{4}: \mathbf{2 5 \%}$ Erythritol $+\mathbf{7 5 \%}$ Sugar & 13 & 30 & 27 & 25 \\
\hline $\mathrm{T}_{5}: \mathbf{1 0 0 \%}$ Stevia & 2 & 7 & 5 & 3 \\
\hline$T_{6}: 75 \%$ Stevia $+25 \%$ Sugar & 7 & 19 & 17 & 13 \\
\hline $\mathrm{T}_{7}: \mathbf{5 0} \%$ Stevia $+\mathbf{5 0} \%$ Sugar & 11 & 27 & 24 & 21 \\
\hline$T_{8}: 25 \%$ Stevia $+75 \%$ Sugar & 10 & 24 & 21 & 19 \\
\hline$T_{9}: 100 \%$ Equal (Aspartame) & 5 & 15 & 12 & 9 \\
\hline$T_{10}: 75 \%$ Equal + $25 \%$ Sugar & 7 & 17 & 14 & 11 \\
\hline $\mathrm{T}_{11}: 50 \%$ Equal $+50 \%$ Sugar & 18 & 35 & 31 & 29 \\
\hline $\mathrm{T}_{12}: 25 \%$ Equal $+75 \%$ Sugar & 10 & 22 & 21 & 18 \\
\hline$T_{13}: 50 \%$ Erythritol $+50 \%$ Stevia & 5 & 10 & 9 & 7 \\
\hline$T_{14}: 50 \%$ Erythritol $+50 \%$ Equal & 3 & 9 & 8 & 5 \\
\hline$T_{15}: 50 \%$ Stevia $+50 \%$ Equal & 2 & 9 & 6 & 4 \\
\hline SEm \pm & 0.97 & 1.03 & 1.06 & 1.08 \\
\hline CD at $5 \%$ & 2.82 & 2.98 & 3.05 & 3.12 \\
\hline
\end{tabular}

Table.2 Effect of different recipe treatments on microbial population dynamics of stored jamun RTS

\begin{tabular}{|c|c|c|c|c|}
\hline \multirow[t]{2}{*}{ Treatments } & \multicolumn{4}{|c|}{ Storage periods (days) } \\
\hline & $\mathbf{0}$ & 30 & 60 & 90 \\
\hline $\mathrm{T}_{0}: 100 \%$ Sugar & 15 & 28 & 25 & 23 \\
\hline$T_{1}: 100 \%$ Erythritol & 11 & 19 & 16 & 14 \\
\hline $\mathrm{T}_{2}: \mathbf{7 5 \%}$ Erythritol + 25\% Sugar & 5 & 9 & 7 & 6 \\
\hline $\mathrm{T}_{3}: \mathbf{5 0 \%}$ Erythritol + 50\% Sugar & 10 & 18 & 15 & 12 \\
\hline $\mathrm{T}_{4}: \mathbf{2 5 \%}$ Erythritol + $75 \%$ Sugar & 12 & 22 & 21 & 19 \\
\hline$T_{5}: 100 \%$ Stevia & 3 & 6 & 4 & 2 \\
\hline$T_{6}: 75 \%$ Stevia $+25 \%$ Sugar & 11 & 20 & 19 & 17 \\
\hline $\mathbf{T}_{7}: 50 \%$ Stevia $+50 \%$ Sugar & 5 & 11 & 9 & 8 \\
\hline $\mathrm{T}_{8}: 25 \%$ Stevia $+75 \%$ Sugar & 13 & 24 & 22 & 20 \\
\hline$T_{9}: 100 \%$ Equal (Aspartame) & 9 & 12 & 11 & 10 \\
\hline$T_{10}: 75 \%$ Equal + $25 \%$ Sugar & 7 & 14 & 10 & 9 \\
\hline $\mathrm{T}_{11}: \mathbf{5 0 \%}$ Equal $+\mathbf{5 0 \%}$ Sugar & 16 & 31 & 28 & 25 \\
\hline$T_{12}: 25 \%$ Equal $+75 \%$ Sugar & 9 & 15 & 13 & 10 \\
\hline $\mathrm{T}_{13}: \mathbf{5 0 \%}$ Erythritol + 50\%Stevia & 6 & 10 & 9 & 7 \\
\hline $\mathrm{T}_{14}: 50 \%$ Erythritol + 50\% Equal & 4 & 7 & 6 & 5 \\
\hline$T_{15}: 50 \%$ Stevia $+50 \%$ Equal & 3 & 6 & 4 & 3 \\
\hline SEm \pm & 0.90 & 0.97 & 1.02 & 1.05 \\
\hline CD at $5 \%$ & 2.61 & 2.80 & 2.95 & 3.04 \\
\hline
\end{tabular}


Table.3 Effect of different recipe treatments on economics of stored jamun nectar

\begin{tabular}{|c|c|c|c|c|}
\hline Treatments & $\begin{array}{c}\text { Cost of } \\
\text { Production } \\
\text { (Rs.) }\end{array}$ & $\begin{array}{c}\text { Gross return } \\
\text { (hundred } \\
\text { bottle) } \\
\text { Rs. }\end{array}$ & $\begin{array}{c}\text { Net return } \\
\text { (hundred } \\
\text { bottle) } \\
\text { Rs. }\end{array}$ & $\begin{array}{l}\text { B:C } \\
\text { ratio }\end{array}$ \\
\hline$T_{0}: 100 \%$ Sugar & 745.1 & 1500 & 754.9 & 1.01 \\
\hline$T_{1}: 100 \%$ Erythritol & 641.6 & 1500 & 858.37 & 1.33 \\
\hline $\begin{array}{c}\mathbf{T}_{2}: \mathbf{7 5 \%} \text { Erythritol }+25 \% \\
\text { Sugar }\end{array}$ & 667.0 & 1500 & 833 & 1.24 \\
\hline $\begin{array}{c}\mathrm{T}_{3}: \mathbf{5 0 \%} \text { Erythritol }+\mathbf{5 0 \%} \\
\text { Sugar }\end{array}$ & 693.05 & 1500 & 806.95 & 1.16 \\
\hline $\begin{array}{c}\mathrm{T}_{4}: \mathbf{2 5 \%} \text { Erythritol + } \mathbf{7 5 \%} \\
\text { Sugar }\end{array}$ & 719.0 & 1500 & 781 & 1.08 \\
\hline$T_{5}: 100 \%$ Stevia & 674.0 & 1500 & 826 & 1.22 \\
\hline$T_{6}: 75 \%$ Stevia + 25\% Sugar & 691.9 & 1500 & 808.1 & 1.16 \\
\hline $\mathrm{T}_{7}: \mathbf{5 0 \%}$ Stevia $+\mathbf{5 0 \%}$ Sugar & 709.8 & 1500 & 790.2 & 1.11 \\
\hline$T_{8}: 25 \%$ Stevia $+75 \%$ Sugar & 727.4 & 1500 & 772.6 & 1.06 \\
\hline$T_{9}: 100 \%$ Equal (Aspartame) & 706.6 & 1500 & 793.4 & 1.12 \\
\hline$T_{10}: 75 \%$ Equal + 25\% Sugar & 716.2 & 1500 & 783.8 & 1.09 \\
\hline $\begin{array}{c}T_{11}: 50 \% \text { Equal + } 50 \% \\
\text { Sugar }\end{array}$ & 725.8 & 1500 & 774.2 & 1.06 \\
\hline $\begin{array}{c}T_{12}: 25 \% \text { Equal }+75 \% \\
\text { Sugar }\end{array}$ & 735.4 & 1500 & 764.6 & 1.03 \\
\hline $\begin{array}{c}\text { T }_{13:} \text { 50\% Erythritol + } \\
\text { 50\% Stevia }\end{array}$ & 657.8 & 1500 & 842.2 & 1.28 \\
\hline $\begin{array}{c}\mathrm{T}_{14}: \mathbf{5 0 \%} \text { Erythritol }+\mathbf{5 0 \%} \\
\text { Equal }\end{array}$ & 673.8 & 1500 & 826.2 & 1.22 \\
\hline $\begin{array}{c}T_{15}: 50 \% \text { Stevia }+50 \% \\
\text { Equal }\end{array}$ & 690.6 & 1500 & 809.4 & 1.17 \\
\hline
\end{tabular}

Economics details for Table 3 and 4: Jamun/Kg- Rs 40, Sugar/Kg- Rs. 30, Citric acid (25 gm)- Rs. 16, Stevia (1 Kg)- Rs.3000, Erythritol (1 Kg)- Rs. 900, Equal (Aspartame 100 tab)- Rs.40, Labour cost (per day)- Rs. 200, Fuel cost- Rs.35, Cap cost ( 100 bottles)- Rs.100. 
Table.4 Effect of different recipe treatments on economics of stored jamun RTS

\begin{tabular}{|c|c|c|c|c|}
\hline Treatments & $\begin{array}{l}\text { Cost of } \\
\text { Production } \\
\text { (Rs.) }\end{array}$ & $\begin{array}{c}\text { Gross } \\
\text { return of } \\
\text { hundred } \\
\text { bottles } \\
\text { (Rs.) }\end{array}$ & $\begin{array}{l}\text { Net return hundred } \\
\text { bottles } \\
\text { (Rs.) }\end{array}$ & B:C ratio \\
\hline$T_{0}: 100 \%$ Sugar & 607.92 & 1500 & 892.08 & 1.46 \\
\hline$T_{1}: 100 \%$ Erythritol & 516.66 & 1500 & 983.3 & 1.9 \\
\hline $\begin{array}{c}\mathrm{T}_{2}: \mathbf{7 5 \%} \text { Erythritol }+25 \% \\
\text { Sugar }\end{array}$ & 539.43 & 1500 & 960.5 & 1.78 \\
\hline$\underset{\text { Sugar }}{\mathrm{T}_{3}: \mathbf{5 0 \%}} \underset{\text { Erythritol }}{+\mathbf{5 0 \%}}$ & 562.22 & 1500 & 937.7 & 1.66 \\
\hline $\begin{array}{c}\mathrm{T}_{4}: \mathbf{2 5 \%} \text { Erythritol }+\mathbf{7 5 \%} \\
\text { Sugar }\end{array}$ & 585.02 & 1500 & 914.9 & 1.56 \\
\hline$T_{5}: 100 \%$ Stevia & 545.52 & 1500 & 954.4 & 1.74 \\
\hline$T_{6}: 75 \%$ Stevia $+25 \%$ Sugar & 561.12 & 1500 & 938.8 & 1.67 \\
\hline $\mathbf{T}_{7}: \mathbf{5 0} \%$ Stevia + 50\% Sugar & 576.72 & 1500 & 923.2 & 1.6 \\
\hline$T_{8}: 25 \%$ Stevia + $75 \%$ Sugar & 592.32 & 1500 & 907.6 & 1.53 \\
\hline$T_{9}: 100 \%$ Equal (Aspartame) & 571.52 & 1500 & 928.4 & 1.62 \\
\hline$T_{10}: 75 \%$ Equal $+25 \%$ Sugar & 581.62 & 1500 & 918.3 & 1.57 \\
\hline$T_{11}: 50 \%$ Equal + 50\% Sugar & 591.72 & 1500 & 908.2 & 1.53 \\
\hline$T_{12}: 25 \%$ Equal $+75 \%$ Sugar & 597.82 & 1500 & 902.1 & 1.5 \\
\hline $\begin{array}{c}T_{13}: 50 \% \text { Erythritol + } \\
50 \% \text { Stevia }\end{array}$ & 531.02 & 1500 & 968.9 & 1.82 \\
\hline $\begin{array}{c}\mathrm{T}_{14}: \mathbf{5 0 \%} \text { Erythritol }+\mathbf{5 0 \%} \\
\text { Equal }\end{array}$ & 546.02 & 1500 & 953.9 & 1.74 \\
\hline $\begin{array}{c}T_{15}: 50 \% \text { Stevia }+50 \% \\
\text { Equal }\end{array}$ & 560.52 & 1500 & 939.4 & 1.67 \\
\hline
\end{tabular}

The data revealed that the highest cost of production of jamun nectar was (745.1) recorded with the treatment $100 \%$ Sugar $\left(\mathrm{T}_{0}\right)$ while, it was lowest (641.6) under the treatment $100 \%$ Erythritol $\left(\mathrm{T}_{1}\right)$. The highest net return (858.3) and benefit: cost ratio (1.33) was recorded in the treatment of $100 \%$ Erythritol $\left(\mathrm{T}_{1}\right)$ while both was $(754.9$ and 1.01) recorded lowest under the treatment $100 \%$ Sugar $\left(\mathrm{T}_{0}\right)$ respectively.

The highest benefit: cost ratio in the treatment of $\mathrm{T}_{1}$ could be attributed to good gross monetary returns and comparatively moderate cost of production that resulted in high benefit: cost ratio. The lowest benefit: cost ratio in treatment $T_{0}$ may be due to lowest gross monetary returns. The present study indicated that considering the benefit: cost ratio, the sugar level can be replaced by alternative sweeteners (in different combination) without much reduction in the benefit: cost ratio.

\section{Benefit: Cost ratio of RTS}

Data pertaining to effect of different recipe treatments on the Benefit: cost ratio of jamun 
RTS beverage is presented Table 4. The highest cost of production of jamun RTS (607.9) was recorded with the treatment $100 \%$ Sugar $\left(\mathrm{T}_{0}\right)$ while, it was lowest (516.6) under the treatment $100 \%$ Erythritol $\left(\mathrm{T}_{1}\right)$. The highest net return (983.3) and benefit: cost ratio (1.9) was recorded in the treatment of $100 \%$ Erythritol $\left(\mathrm{T}_{1}\right)$ while both was $(892.08$ and 1.46) recorded lowest under the treatment $100 \%$ Sugar $\left(\mathrm{T}_{0}\right)$ respectively.

The highest benefit: cost ratio in the treatment of $T_{1}$ could be attributed to good gross monetary returns and comparatively moderate cost of production that resulted in high benefit: cost ratio. The lowest benefit: cost ratio in treatment $T_{0}$ may be due to lowest gross monetary returns. The present study indicated that considering the benefit: cost ratio, the sugar level can be replaced by alternative sweeteners (in different combination) without much reduction in the benefit: cost ratio.

\section{References}

Choudhary, M.L. and Dikshit, S.N. (2006). Studies on shelf life of guava beverages. Current Agriculture, 30(1/2): 75-78.

Goyle, A. and Ojha, P. (1998).Effect of storage on vitamin $\mathrm{C}$, microbial load and sensory attributes of orange juice. J. Food Sci. \& Technol. 35(4): 346348.

Joshi, S.G. (2001). Medicinal plants, New Delhi, Oxford and IBH Publishing Co.Ltd.

Li, Z., Alli, I. and Kermasha, S. (1989). Use of acidification, low temperature and sorbates for storage of orange juice. $J$. Food Sci., 54(3): 674-678.

Livesey G. (2006). Glycaemic response and toleration. In: O'Brien-Nabors L editor. Alternative Sweeteners. $4^{\text {th }}$ ed. Florida: CRC Press. Pp. 1-15.
Markam, R. and Singh, V. (2012). Studies on microbial and sensory quality of custard apple RTS beverage. Asian J. of Hort., 7(2): 460-464.

Pathak, R.Y. and Pathak, R.A. (1993). Improvement of minor fruits chapter in Advances in Horticulture book, Malhotra Publishing House. (1): 407422.

Prince, P.S.M., Kamalakkanan, N. and Menon, V.P. (2003). Syzygium cuminii Skeels seed extracts reduce tissue damage in diabetic rat brain. $J$. Anthropol., 84: 205-209.

Rao, N.S.S. (1988). Biological Nitrogen fixation. Oxford and I.B.H. Pub. Co., New Delhi. retentions of pomegranate juice. Ind. Fd. Pack., 41(5):5-8.

Schmidt, E.L. and Caldwell, A.C. (1967). A practical manual of Soil Microbiology Laboratory Methods. Food and Agric. Organization of the United Nations Soils Bull., 72-75.

Thakur, N.K., Lal K., B.B. and Joshu, V.K. (2000). Effect of Different conditions of storage on physico-chemical and microbiological qualities of debittered Kinnow Juice concentrate. J. Food Sci. \& Technol., 37(4): 415-418.

Upale, K., Patil, R.C., Kamble, A.K., Raut, N.B. and Kuknoor, L. (2010a). Standardization of recipes for ready-toserve (RTS) Jamun beverages. $J$. Ecobiology, 27(3/4): 213-216.

Upale, K., Patil, R.C., Kamble, A.K., Raut, N.B. and Kuknoor, L. (2010b). Standardization of recipes for jamun nectar. J. Ecobiology, 27(3/4): 311315.

Yadav, A., Chandra, S., Singh, J. and Kumar, V. (2012). Effect of storage conditions on physico-chemical, microbial and sensory quality of ready-to-serve banana beverage. Madras Agril. J., 100(1/3): 251-256. 
How to cite this article:

Bhawna Panda, H. G. Sharma, Abhay Bisen and Krishnakant Rajak. 2019. Microbial and Economical Studies of Jamun Beverages Prepared by Alternative Sweeteners. Int.J.Curr.Microbiol.App.Sci. 8(12): 187-195. doi: https://doi.org/10.20546/ijcmas.2019.812.027 